\title{
Need and scarcity of water in India
}

\section{Editorial}

Water is one of the important object on the planet earth which is used by all the living entities. Nearly 62 billion liters per day sewage is generated in urban areas while only 23.277 billion liters is treated. On the other hand, 0.6 billion people lack sanitation facilities in rural area. Total $61.5 \%$ of the Indian population is rural and dependent on agriculture amounting to one-third of the country's GDP. But the state of agriculture in the nation has hit a stagger pertaining to a complex set of factors viz. global warming, competitive land use, and lack of basic infrastructure. As per a Ministry of Agriculture report released in 2014 , only $46 \%$ of the cultivated land in India is irrigated.

It is easy to be taken in by the name and see this untreated wastewater as literal waste. However, to deal with high demand with finite resources, wastewater discarded into the environment, if treated, can help supply of water needs of various sectors. Modern technologies make it both possible and feasible to reclaim raw materials from wastewater, which in turn can be used as resources in industrial, agricultural or other applications.

The supply of drinking water and adequate sanitation are rudimentary requirements for upgrading the quality life and improvement of prolific competence among people. The water is tapped for domestic and industrial purposes from rivers, streams, wells and lakes. As per current scenario, about $80 \%$ of domestic water comes out as wastewater. In most of the cases, this wastewater is let out unprocessed/untreated and it either sinks into the ground which contaminates the ground water or discharged into the natural drainage system causing pollution surface water.

According to the Central Pollution Control Board (CPCB) New Delhi, the municipal sewage may be defined as "Mostly liquid waste originating from a community; may be composed of domestic wastewaters and/or industrial discharges". The municipal sewage is main cause of water pollution in India. Approximately $78 \%$ of the urban population has access to safe drinking water and about $38 \%$ of the urban population has access to sanitation services. With the enhancement of drinking water supply to urban areas, the wastewater generation is increasing. If this wastewater is not collected, treated and disposed properly, it will directly contribute to pollution of the locally available freshwater supplies. Furthermore, the increasing results of untreated wastewater can have broad deteriorating effects on community health and environment. The wastewater management is a significant chunk of the Sustainable Development Goals (SDG, UNDP). The Sustainable Development Goals are a collection of 17 global goals set by the United Nations Development Programme. Sustainable Development Goals 6 has particular goals on sharing the proportion of untreated wastewater and substantially increasing recycling and safe reuse globally as well as supporting countries in wastewater treatment, reduce, re-cycling and re-use technologies.

As per reports, groundwater in India depleted at 10-25 mm annual between 2002 and 2016. Average rainfall declined from 1,050 $\mathrm{mm}$ in the summer cropping season (1970) to less than $1,000 \mathrm{~mm}$ (2015).
Special Issue - 2018

\author{
Ashok K Rathoure \\ Ecosystem Resources Management Pvt. Ltd.; Eco Chem Sales \& \\ Services, India
}

Correspondence: Ashok K Rathoure, Mayashivraj Sadan, Gupta Colony, Hardoi-24I00I, (UP) India, Tel +91945050 I47I, Email asokumr@gmail.com

Received: August 23, 2018 | Published: August 30, 2018

In the winter cropping season, average rainfall declined from 150 $\mathrm{mm}$ (1970) to about $100 \mathrm{~mm}$ (2015). Dry days during the monsoons have increased, from $\sim 40 \%$ to $45 \%$ in 2015 . The number is further aggravating because of the constant decline in the freshwater sources in India. As per the recently released Water Management Index of the NITI Aayog, India is facing one of the worst water crises and a number of cities are expected to run out of water by 2020 .

Various state governments with the support and guidance from the Centre are working to utilize the available water for irrigation efficiently. Schemes like Pradhan Mantri Krishi Sinchayee Yojana and Har Khet ko Pani are targeting to increase the water-use efficiency in the fields and double the farmers' income substantially.

The emphasis has been on the availability, quality and sustainability of freshwater, largely used for drinking/ domestic purposes in India. The decades of habitual complacency with water being supplied or provided for or accessed easily through extracting the same from common property resources (CPR) have shaken the surface or subground bases. The tangible reasons for the crisis have been recognized as the extreme demand for water coming up from a huge, growing and frequently metropolitan population; depleting groundwater levels due to tedious misuse; polluting water stream; mismanaging wastewater; negligence of protecting and/or promoting water harvesting systems; and meager strategy and its execution. There is an urgent need for water conservation, uses of alternatives like rain water harvesting; strong policy towards water uses; recycling, reuse/condensation; waste heat recovery; desalination plants; better waste water treatment practices; treated water as raw material for other industry where it can be used, etc. Without water, life cannot exist on the planet and if we misuse the water, it will be contaminated and of no use.

\section{Acknowledgements}

None.

\section{Conflict of interest}

Author declares that he has no conflict of interest. 